\title{
EXPRESSÃO GÊNICA DE FAS EM CMSP DE INDIVÍDUOS PORTADORES DE PERIODONTITE CRÔNICA.
}

\section{$\underline{\text { Santos R A }}{ }^{1}$; Trindade $\mathrm{SC}^{2}$; Santos RPB ${ }^{3}$; Pimentel ACM ${ }^{4}$; Xavier MT ${ }^{5}$; Filho $\mathrm{PCC}^{6}$}

1. Ricardo Almeida dos Santos PIBIC/FAPESB, Graduando em Odontologia, Universidade Estadual de Feira de Santana, e-mail: ricardoalmeida_s@ @otmail.com

2. Soraya Castro Trindade, Departamento de Saúde, Universidade Estadual de Feira de Santana, e-mail: soraya@uefs.br

3. Rebeca Pereira Bulhosa Santos, mestranda em imunologia, Universidade Federal da Bahia, e-mail: biorebecabulhosa@gmail.com

4. Ana Carla Montinho Pimentel, doutoranda em imunologia, Universidade Federal da Bahia, e-mail: anacpimentel_ba@hotmail.com

5. Marcia Tosta Xavier, Departamento de bioquímica, Universidade Federal da Bahia, e-mail: tostamarcia@gmail.com

6. Paulo Cirino de Carvalho Filho, Doutor em imunologia, Universidade Federal da Bahia, e-mail: pauloccf@yahoo.com

\section{PALAVRAS-CHAVE: PERIODONTITE CRÔNICA; FAS; APOPTOSE}

\section{INTRODUÇÃOO}

O conhecimento atual sobre a patogênese da Periodontite sugere que ela decorra de interações complexas entre a ação de microorganismos subgengivais e a resposta imunológica do hospedeiro. [GREENSTEIN G' 2000] [O’BEIRNE G, 1996]. Componentes de Porphyromonas gingivalis modulam a resposta imune do hospedeiro por meio de indução de apoptose de linfócitos T e macrófagos. [LINDHE, J. 1999] .

A apoptose associada com a destruição celular é um fenômeno presente nos sítios de inflamação crônica bacteriana na gengiva humana e é de grande importância na regulação da inflamação nas mucosas. [TONETTI, M.S, 1998]. Uma das principais proteínas pró-apoptóticas é o Fas. A proteína Fas pertence à superfamília do receptor do TNF. O gene da proteína Fas (APO1 / CD95), localizado no braço longo do cromossomo 10, na região 2.3 (10q2.3), transcreve um receptor transmembrânico composto de 319 aminoácidos e peso molecular de 40KDa a 50KDa o qual, após sua ligação com o Fas ligante, induz apoptose por meio de seu domínio citoplasmático. [LICHTER, P , 1992] [JU, S.T et al ,1995].

Diante disso pretende-se observar a expressão gênica de FAS em CMSP cultivadas sobestímulo de Porphyromonas gingivalis na periodontite crônica. 


\section{MATERIAL E MÉTODOS OU METODOLOGIA (ou equivalente)}

Foi proposto um estudo experimental com pessoas com idades acima de 18 anos e de ambos os sexos, que buscaram voluntariamente os ambulatórios do curso de Odontologia da Universidade Estadual de Feira de Santana.

O sangue dos indivíduos foi coletado num volume de $20 \mathrm{~mL}$, por punção venosa na fossa ante-cubital com tubo à vácuo estéril (BD-SP) com heparina e submetido a centrifugação por gradiente de densidade. Células mononucleares de sangue periférico (CMSP) foram cultivadas em placas de 24 poços por $48 \mathrm{~h}$ a $37^{\circ}$, em estufa de $\mathrm{CO} 2$, sob o estímulo da proteína HmuY de Porphyromonas gingivalis ATCC33277. Depois da avaliação da qualidade e quantidade de RNA o próximo passo foi a análise das amostras por meio da técnica de microarray.

Foi realizada uma análise descritiva dos dados relativos a gênero, idade e descritores clínicos visando a caracterização da amostra. Em seguida, foi utilizado o teste nãoparamétrico de Mann-Whitney e t bicaudal para a comparação dos dados entre os grupos.

\section{RESULTADOS E/OU DISCUSSÃO}

Foram incluídos apenas 16 indivíduos, 8 com periodontite crônica grave (PC) e 8 sem periodontite (SP). A média de idade dos participantes do grupo PC foi de 43.88 $\pm 13,9$ anos, enquanto a média de idade dos participantes do grupo SP foi de $36.63 \pm 10.8$ anos. Cada grupo foi composto de dois homens e seis mulheres. Não houve diferença estatisticamente significante na média da idade $(\mathrm{p}=0,22)$, na proporção de indivíduos do sexo masculino e feminino $(p=1,00)$ e na quantidade de dentes presentes na boca $(\mathrm{p}=0,98)$ entre os dois grupos, demonstrando que ambos foram homogêneos no que diz respeito a estas covariáveis (Tabela 1). Em contrapartida, como esperado, houve diferença nos descritores clínicos periodontais, como pode ser observado na tabela 1.

\begin{tabular}{|c|c|c|c|}
\hline & $\overline{\text { SP }}$ & $\overline{\mathbf{P C}}$ & $\overline{\mathbf{P}}$ \\
\hline Número de homens/mulheres & $2 / 6$ & $2 / 6$ & 1.000 \\
\hline Idade (anos) (média \pm DP) & $36.63 \pm 10.8$ & $43.88 \pm 13,9$ & 0.223 \\
\hline $\begin{array}{l}\text { Número de dentes presentes na boca } \\
(\text { média } \pm \text { DP })\end{array}$ & $20.13 \pm 6.2$ & $20.31 \pm 6.5$ & 0.983 \\
\hline \% SS (média \pm DP) & $8.78 \pm 11.49$ & $46.23 \pm 14.43$ & 0.001 \\
\hline$\%$ PS $\geq 4$ (média \pm DP $)$ & $1.01 \pm 1.55$ & $16.33 \pm 11.44$ & 0.000 \\
\hline
\end{tabular}




\section{DP Desvio Padrão, SS Sangramento a Sondagem, PS Profundidade de Sondagem, NIC nível de Inserção Clínica.} PADRÃO DE EXPRESSÃO DE mRNA - "HEAT MAP”

Foram identificadas diferenças no padrão de expressão gênica global entre as amostras de PC e SP, especialmente nas amostras de CMSP nos grupos PC e SP estimulados com rHmuY (Figura 1).

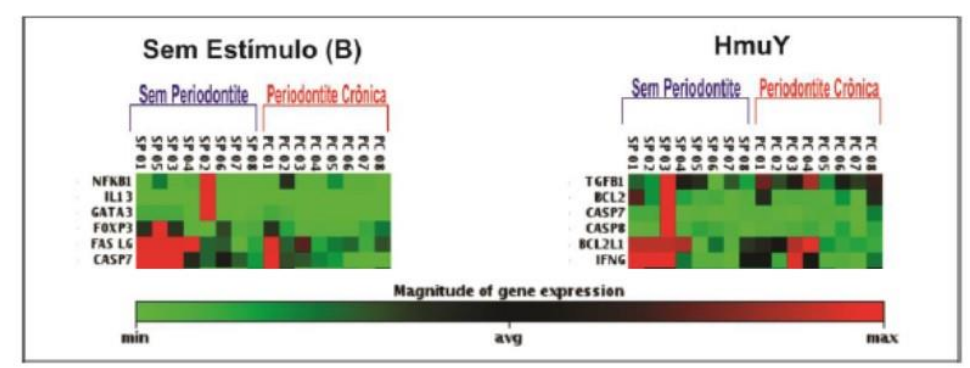

Figura 1: - Perfil de Expressão de mRNA - “Heat Map”. Iden tificação de clusters gênicos envolvidos em mecanismos de apoptose, proteínas de choque térmico, citocinas, quimiocinas e fatores de transcrição por CMSP de pacientes com periodontite crônica (PC) e sem (SP) sob estímulo de rHmuY de Porphyromonas gingivalis e na ausência de estímulos. O gradiente de cor verde-preto-vermelho representa níveis relativos de expressão gênica, indicando "UnderEven-Over" regulação, respectivamente. Em destaque, a expressão gênica de IL-1 $\beta$ nas células dos indivíduos de ambos os grupos, com e sem estímulo.

As células dos indivíduos do grupo PC apresentaram menor expressão relativa de FAS do que as células do grupo SP, quando cultivadas com a proteína rHmuY, com uma tendência à significância estatística $(0.05<\S p<0.1)$, como pode ser observado na figura 2. Não foram encontradas diferenças estatisticamente significantes entre os grupos para a expressão de FAS por células não estimuladas (Figura 3).

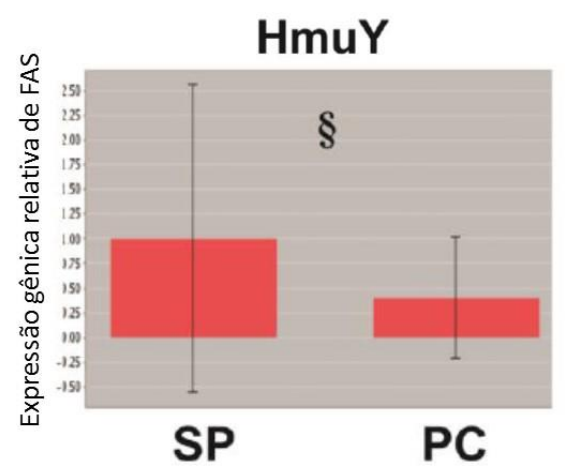

Figura 2: Expressão de mRNA para o gene relacionado ao Receptor da superfamília TNF, Membro 6 (FAS) por células mononucleares do sangue periférico cultivadas em presença de rHmuY. SP: Sem Periodontite; PC: Periodontite crônica. $§ p<0.1$.

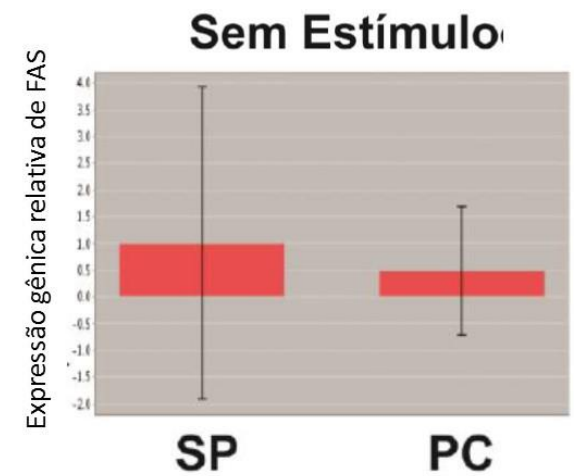

Figura 2: Expressão de mRNA para o gene relacionado ao Receptor da superfamília TNF, Membro 6 (FAS) por células mononucleares do sangue periférico cultivadas sem estímulo antigênico. SP: Sem Periodontite; PC: Periodontite crônica.

Os resultados do presente estudo demonstraram a capacidade HmuY de Porphyromonas gingivalis atuar na expressão de mRNA para genes que participam da sinalização 
molecular de apoptose. Assim, é possível que este fator de virulência do patógeno possa aumentar a sobrevivência de células inflamatórias por inibição de apoptose, mantendo desta forma um estado crônico de inflamação tecidual.

\section{CONCLUSÃO}

A proteína recombinante HmuY de $P$. gingivalis diminui a expressão gênica relativa para FAS em CMSP de indivíduos do grupo PC.

\section{REFERENCIAS}

GREENSTEIN G. Nonsurgical periodontal therapy in 2000: a literature review. $\boldsymbol{J} \boldsymbol{A m}$ Dental Assoc, 2000;131:1580-92.

O'BEIRNE G, JOHNSON RH, PERSSON GR, SPEKTOR MD. Efficacy of sonic toothbrush on inflammation and probing depth in adulth periodontiti. J Periodontol, 1996;67:900-08.

LINDHE, J. Tratado de Periodontia Clínica e Implantodontia Oral, GuanabaraKoongan,1999.

TONETTI, M.S.; CORTELLINI, D.; LANG, N.P. In situ detection of apoptosis at sites of chronic bacterially induced

inflamation in human gingiva. Infection and Immunity,v.66, p.5190-5195, 1998.

LICHTER, P.; WALCZAK, H.Ç.; WITZ, S.; BERHMANN, I.; KRAMMER, P.H. The human APO-1 antigen maps to 10q23, a region which is sythenic with mouse chromossome. Genomics. v.14, p.179-80, 1992.

JU, S.T.; PANKA, D.J.; CUI, H.E.R.; EL-KHATIB, M.; SHER, D.H.; STANGER, B.Z.; MARSHAK-ROTHSTEIN, A. Fas (CD95)/FasL interactions required for programmed cell death after T-cell activation. Nature. v.373, p.444-448, 1995. 